\title{
Investigation of the Whitening Composition for the Porcelain Stoneware Tiles
}

\author{
N. T. SELLI* \\ Eczacibasi Building Products Co. VitrA Innovation Center Bozuyuk/Bilecik, Turkey
}

\begin{abstract}
A synthetic whitening composition is proposed as a whitening agent of porcelain tile body with a certain amount for the turning the body colour into whiteness. Active component used in the agent is zirconium silicate and this component is affected by the market speculation.This situation increases considerably the production costs. For these reasons an alternative whitening composition is required. The aim of the study is to prepare new whitening composition without zirconium silicate, with controlling crystalline phases in the porcelain stoneware tile, and to carry out characterization studies (such as XRD, SEM and EDX) and to correlate the whiteness value and the amount and type of crystalline phases in the porcelain tiles.
\end{abstract}

DOI: 10.12693/APhysPolA.127.1202

PACS: $81.05 . J e$

\section{Introduction}

There has been an increase in the production of ceramic coating materials around the world. Turkey ranks as the third in Europe and ninth in the world, when it comes to the production of coating materials (floor tiles, wall tiles, porcelain tiles and decoration products), with a production capacity of about 400 million $\mathrm{m}^{2} /$ year [1] The production of ceramic tiles has been rapidly increasing throughout the world. This increase has occurred especially in the production of colorful porcelain tiles with very dark and very light colors, due to the better technical and aesthetic properties thereof when compared to other products. Moreover, the increase in porcelain tile production is expected to get higher and higher in the years to come. Due to the continuous increase in porcelain tile production capacity and to the competitive environment, both the manufacturers and the researchers focus on the studies on the development of production technologies, as well as on reducing the costs. The number of studies on the use of alternative raw material sources having lower costs in the production of ceramic tiles has increased recently $[2,3]$. In addition to these, more environmentally friendly products are achieved thanks to the studies conducted on the utilization of waste materials, and especially for reducing energy costs [4]. We, as Eczacibasi Vitra Karo, also perform such studies and have an understanding of sustainable production by reducing the costs and doing less harm to the environment. Particularly, in super white and ultra-white porcelain tiles, the fact that zirconium silicate, which is added into the raw material mixture and has a whitening/bleaching effect, is imported, both increases the costs and makes the production dependent on outside sources. Production dependent on foreign sources, causes interruptions in

*e-mail: neslihan.tamsu@eczacibasi.com.tr the production in case there is any problem in shipping. Besides, zirconium silicate, which is used in the whitener, has a variable price, since it is the most affected product by the market speculations. Due to the above reasons, in the present study, the subject of the project is to develop alternative raw material compositions having whitening effect, to replace zirconium silicate, and hence to lower porcelain tile costs, in order to reduce the negative impact of zirconium silicate on the profitability.

\section{Experimental procedure}

First, chemical analyses have been carried out on the whitening agent purchased abroad, in order for our raw materials to have the same color, size, and water absorption properties as those of the imported whitening composition used for bleaching the porcelain tiles. The details of the chemical composition are given in Table I.

TABLE I

Chemical composition of the standard body mix (wt.\%).

\begin{tabular}{c|c|c|c|c|c|c|c|c}
\hline \hline $\mathrm{Na}_{2} \mathrm{O}$ & $\mathrm{MgO}$ & $\mathrm{Al}_{2} \mathrm{O}_{3}$ & $\mathrm{SiO}_{2}$ & $\mathrm{~K}_{2} \mathrm{O}$ & $\mathrm{CaO}$ & $\mathrm{Fe}_{2} \mathrm{O} 3$ & $\mathrm{ZrO}$ & $\mathrm{A} . \mathrm{Z}$ \\
\hline 0.59 & 0.73 & 79.59 & 9.27 & 0.33 & 1.62 & 0.24 & 6.88 & 0.14
\end{tabular}

In order to achieve the same whitening effect in our porcelain structures without using zirconium silicate, experimental studies have been conducted for obtaining our own whitening composition by forming crystalline structures with whitening effect, which can be obtained in the structure by adding various agents. The whitening composition given in Table I is added into standard tile (Uni-ivory) mixture in an amount of $7 \%$, and thus, $L^{*}, a^{*}, b^{*}$ color values, i.e. the desired light colors to be obtained, are achieved. To that end, the composition, obtained after the addition of the whitener into the standard porcelain tile structure is analyzed with respect to the types and amounts of formed phases, using SEM (Scanning Electron Microscope) analysis and EDX analysis (chemical analysis).

New compositions were prepared by wet grinding. Slips were dried at $110^{\circ} \mathrm{C}$. The obtained powders were 
moisturised with 5 wt.\% water. The pellets with $50 \mathrm{~mm}$ diameter and $6 \mathrm{~mm}$ thickness were prepared by uniaxial pressing at a forming pressure of 44 bar (Nannetti Press, Hydraulic Laboratory Press Mignon S, Italy). The colour of the new composition and standard was measured by a spectrometer (Minolta CR, 300 Colormeter). The sample microstructures were examined by scanning electron microscopy (EVO-50, Carl-Zeiss, Germany). The crystalline phases were identified by $\mathrm{X}$-ray diffraction and quantified by rational analysis. $L^{*}, a^{*}, b^{*}$ color values, was measured by a spectrometer (Minolta CR, 300 Colormeter).

\section{Results and discussion}

The scanning electron microscope view of the standard porcelain tile structure, with whitener being added, is presented in Fig. 1. The crystalline phases and the types thereof have been determined by the EDX analyses (chemical analyses) performed using SEM (Fig. 2). The chemical analysis (Fig. 2) shows the presence of peaks of calcium $(\mathrm{Ca})$, aluminum $(\mathrm{Al})$, and silicon $(\mathrm{Si})$ in EDX diagram (Fig. 2, drawing No. 2) of round crystals, which, in turn, shows that these round crystal forms are anor- thite crystals. In EDX analysis of needle-like crystalline structures (Fig. 3, drawing No. 3), silicon ( $\mathrm{Si}$ ) and aluminum $(\mathrm{Al})$ peaks are seen, which indicates the presence of mullite crystals. In angled and irregular structures, on the other hand, silicon ( $\mathrm{Si}$ ) peaks show the presence of quartz (Fig. 3, drawing No. 1).

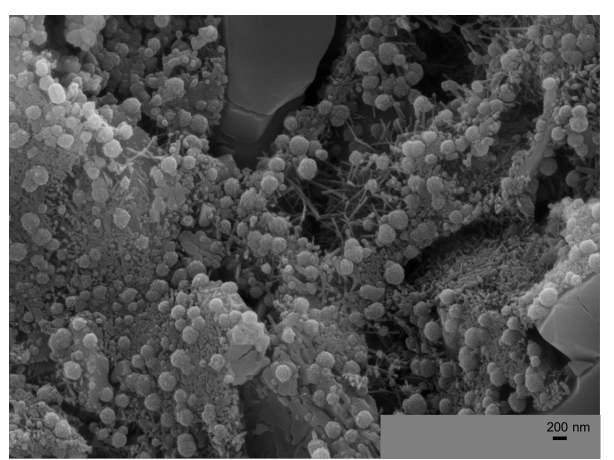

Fig. 1. The microstructure analysis of the porcelain tile body with standard whitening composition.

Comparison of the properties of the new whitening composition (Q-10)

TABLE II and standard whitening composition.

\begin{tabular}{c|c|c|c|c|c|c|c|c|c}
\hline \hline Compositions & $\begin{array}{c}\text { Quartz } \\
{[\%]}\end{array}$ & $\begin{array}{c}\text { Anorthite } \\
{[\%]}\end{array}$ & $\begin{array}{c}\text { Glassy } \\
\text { Phase } \\
{[\%]}\end{array}$ & $\begin{array}{c}\text { Mullite } \\
{[\%]}\end{array}$ & $\begin{array}{c}\text { Dimension } \\
{[\mathrm{mm}]}\end{array}$ & $\begin{array}{c}\text { Water } \\
\text { Absorption } \\
{[\%]}\end{array}$ & $L^{*}$ & $a^{*}$ & $b^{*}$ \\
\hline $\begin{array}{c}\text { Q-10 } \\
\begin{array}{c}\text { Whitening } \\
\text { Composition }\end{array}\end{array}$ & 10 & 9.63 & 65.95 & 14 & 45.99 & 0.034 & 85.7 & 1.01 & 8.05 \\
\hline $\begin{array}{c}\text { STD-whitening } \\
\text { composition }\end{array}$ & 29.16 & 7.48 & 57.07 & 6.29 & 46.25 & 0.059 & 85.1 & 1.07 & 7.83 \\
\hline
\end{tabular}

As seen, phase studies have been conducted on imported porcelain tiles with whitener addition. New formulas are formed for producing the tiles of desired whiteness within our own firm. In the new formulas, $\mathrm{CaO}$, $\mathrm{Al}_{2} \mathrm{O}_{3}$ and whiter national feldspars are added as the raw material instead of zirconium silicate, thereby increasing the amount of anorthite phase, and thus different formula studies have been performed based on the hypothesis that the structure will be whiter. The studies have concluded that the formula coded " $\mathrm{Q}-10$ " is the most suitable composition which is compatible with water absorption value standards and which does not have any problem in terms of size. Super white compositions have been prepared by adding $7 \%$ whitening agent into the standard Uni-ivory white composition. Crystalline phase amounts in the porcelain tiles with Q-10 whitener and with imported whitener addition, color values of the porcelain tiles, as well as sizes and water absorption values thereof, are given in Table II.

According to these results, the amount of glassy phase is increased since the rate of melting feldspat is increased; and due to the use of $\mathrm{CaO}$-containing compositions, the amount of anorthite phase is increased, when compared to the standard. The increase in anorthite amount has ensured the white color value range, as the one provided by the imported material, without requiring the use of zirconium silicate. The scanning electron microscope view of the super white porcelain tile structure with the addition of the whitening composition (Q-10) developed by our own means is given in Fig. 3 .

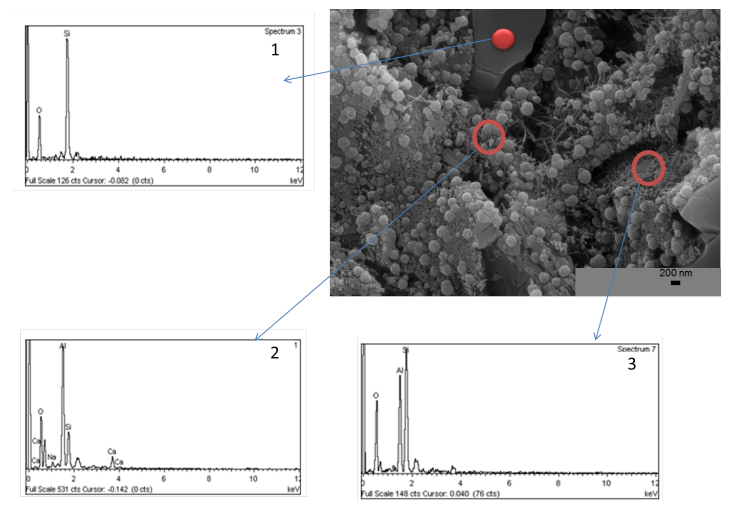

Fig. 2. The microstructure and EDX analyses of the porcelain tile body with standard whitening composition.

The crystalline phases and the types thereof have been 


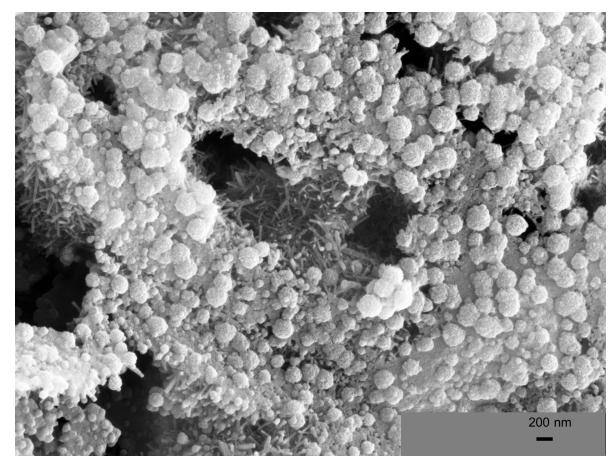

Fig. 3. The microstructure of the porcelain tile body with Q-10 whitening composition.

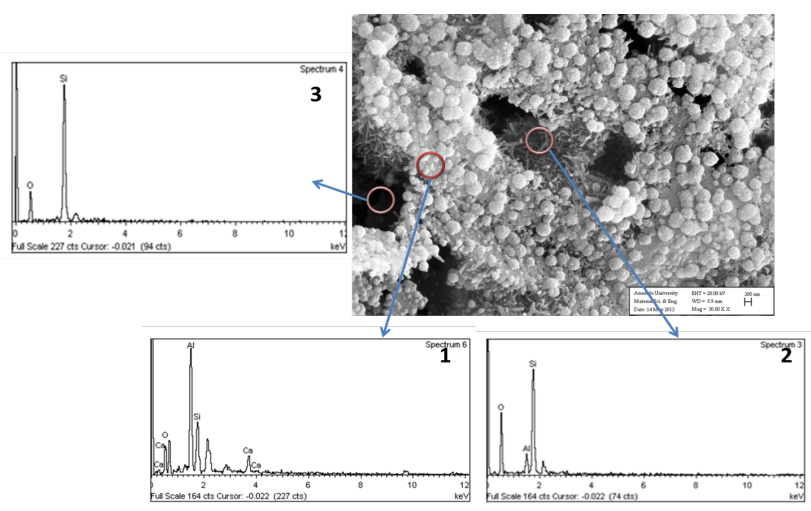

Fig. 4. The microstructure and EDX analyses of the porcelain tile body with Q-10 whitening composition.

determined by the EDX analyses (chemical analyses) performed from scanning electron microscope analysis (Fig. 4). The chemical analysis (Fig. 4) performed from scanning electron microscope shows the peaks of calcium $(\mathrm{Ca})$, aluminum $(\mathrm{Al})$, and silicon $(\mathrm{Si})$ in EDX analysis (Fig. 4, drawing No. 1) of round crystals, which, in turn, shows that these round crystal forms are anorthite crystals. In EDX analysis of rod-like/needle-like crystalline structures (Fig. 4, drawing No. 2), silicon (Si) and aluminum $(\mathrm{Al})$ peaks overlap with one another, and this indicates the presence of mullite crystals. In angled and irregular structures, on the other hand, silicon $(\mathrm{Si})$ peaks indicate quartz crystals (Fig. 4, drawing No. 3). According to these results due to increase of the amount of feldispars and $\mathrm{CaO}$, increases the amount of glassy phase, by the direct increase of the amount of anorthite.

\section{Conclusions}

In this study, the zirconium silicate crystals were substituted with formed anorthite crystals and the amount of the these crystals was increased. It has been shown that the increase of amount of anorthite crystals provides whitening effect without using zirconium silicate. The newly developed recipe is used in porcelain stoneware production line with lower cost (Table III).
TABLE III

Comparison of the cost of the new whitening composition (Q-10) and standard whitening composition.

\begin{tabular}{c|c|c}
\hline $\begin{array}{c}\text { Former cost } \\
\text { [euro/ton] }\end{array}$ & $\begin{array}{c}\text { New cost } \\
\text { [euro/ton] }\end{array}$ & $\begin{array}{c}\text { Difference } \\
{[\%]}\end{array}$ \\
\hline 875 & 525 & 40
\end{tabular}

Therefore, new whitening composition can be successfully used as a substitute of the standard whitening composition with the zirconium silicate. The newly developed composition has been prepared without using imported zirconium silicate, which has remarkably decreased the costs, and also eliminated the dependence on foreign materials.

\section{References}

[1] Ö.N. Zehra, Dünya Seramik Kaplama Malzemeleri Sektörüne Genel Bakış, Kasim 2012.

[2] V. Bozkurt, A. Kara, Y. Ucbas, K. Kayac1, M. ve Ciftci, Ind. Ceram. 26, 87 (2006).

[3] F. Andreola, L. Barbieri, E. Karamanova, I. Lancellotti, M. Pelino, Ceram. Int. 34, 1289 (2008).

[4] A.M. Segadaes, M.A. Carvalho, W. Acchar, Appl. Clay Sci. 30, 42 (2005). 